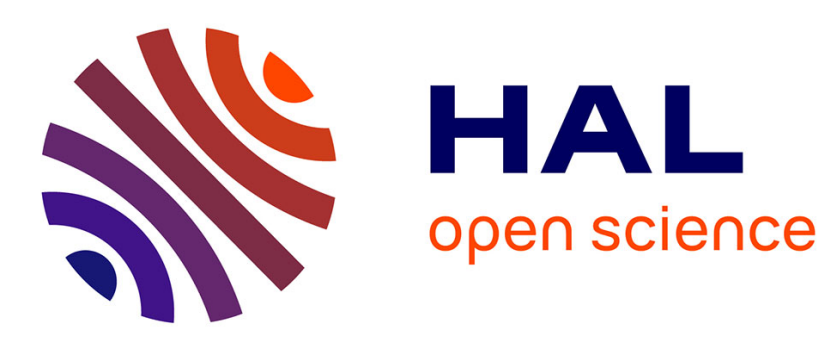

\title{
Ion Pair Binding Functionalised Gold Nanoparticles
}

\author{
Jonathan William Steed, Maria H. Filby
}

\section{To cite this version:}

Jonathan William Steed, Maria H. Filby. Ion Pair Binding Functionalised Gold Nanoparticles. Supramolecular Chemistry, 2009, 21 (05), pp.422-427. 10.1080/10610270802165951 . hal-00513532

\section{HAL Id: hal-00513532 \\ https://hal.science/hal-00513532}

Submitted on 1 Sep 2010

HAL is a multi-disciplinary open access archive for the deposit and dissemination of scientific research documents, whether they are published or not. The documents may come from teaching and research institutions in France or abroad, or from public or private research centers.
L'archive ouverte pluridisciplinaire HAL, est destinée au dépôt et à la diffusion de documents scientifiques de niveau recherche, publiés ou non, émanant des établissements d'enseignement et de recherche français ou étrangers, des laboratoires publics ou privés. 


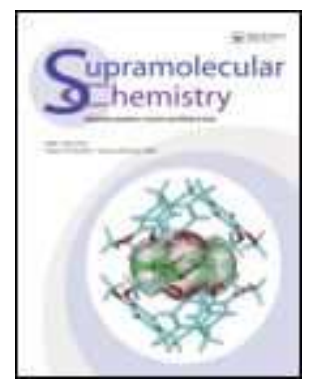

\section{Ion Pair Binding Functionalised Gold Nanoparticles}

\begin{tabular}{|c|c|}
\hline Journal: & Supramolecular Chemistry \\
\hline Manuscript ID: & GSCH-2008-0018.R1 \\
\hline Manuscript Type: & Full Paper \\
\hline $\begin{array}{r}\text { Date Submitted by the } \\
\text { Author: }\end{array}$ & 22-Apr-2008 \\
\hline Complete List of Authors: & $\begin{array}{l}\text { Steed, Jonathan; Durham University } \\
\text { Filby, Maria; Durham UIniversity, Chemistry }\end{array}$ \\
\hline Keywords: & nanoparticles, anion binding, ion pair binding, gold \\
\hline \multicolumn{2}{|c|}{$\begin{array}{l}\text { Note: The following files were submitted by the author for peer review, but cannot be converted } \\
\text { to PDF. You must view these files (e.g. movies) online. }\end{array}$} \\
\hline Fig1.skc & \\
\hline
\end{tabular}

\section{今 ScholarONE" \\ Manuscript Central}


1

2

3

4

5

6

7

10

11

12

13

14

15

16

17

18

19

20

21

22

23

24

25

26

27

28

29

30

31

32

33

34

35

36

37

38

39

40

41

42

43

44

45

46

47

48

49

50

51

52

53

54

55

56

57

58

59

60

Maria H. Filby and Jonathan W. Steed ${ }^{*}$

Ion Pair Binding Functionalised Gold Nanoparticles

Amidopyridyl functionalised gold nanoparticles bind to both anions and cations

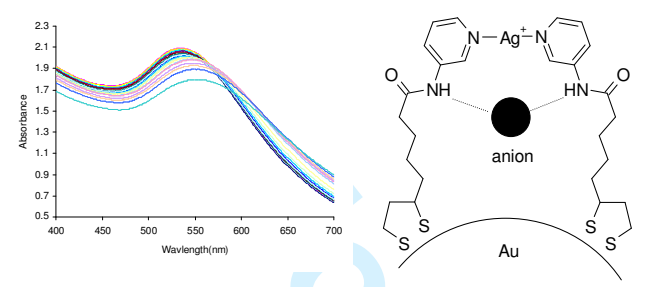




\section{Supplementary Material}

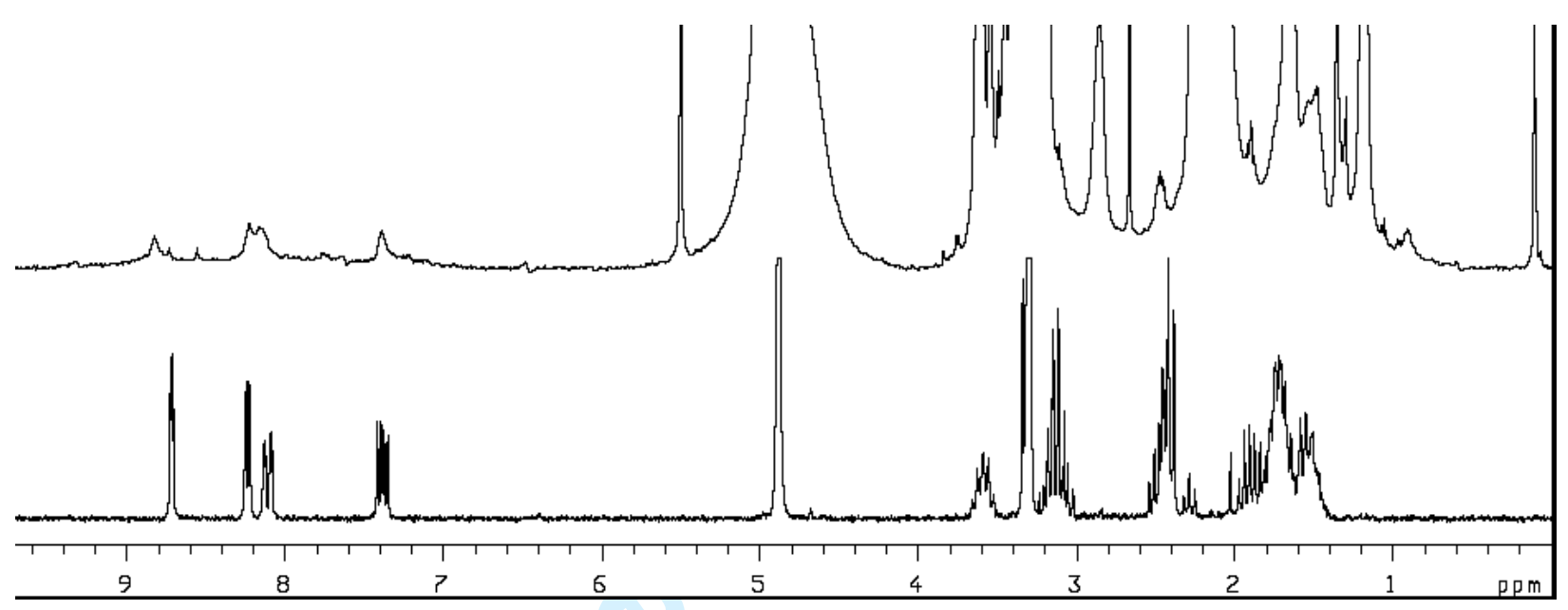

Figure S1. ${ }^{1}$ H NMR spectra of functionalised gold nanoparticles 3 (top) and free ligand (bottom) in methanol- $d_{4}$.

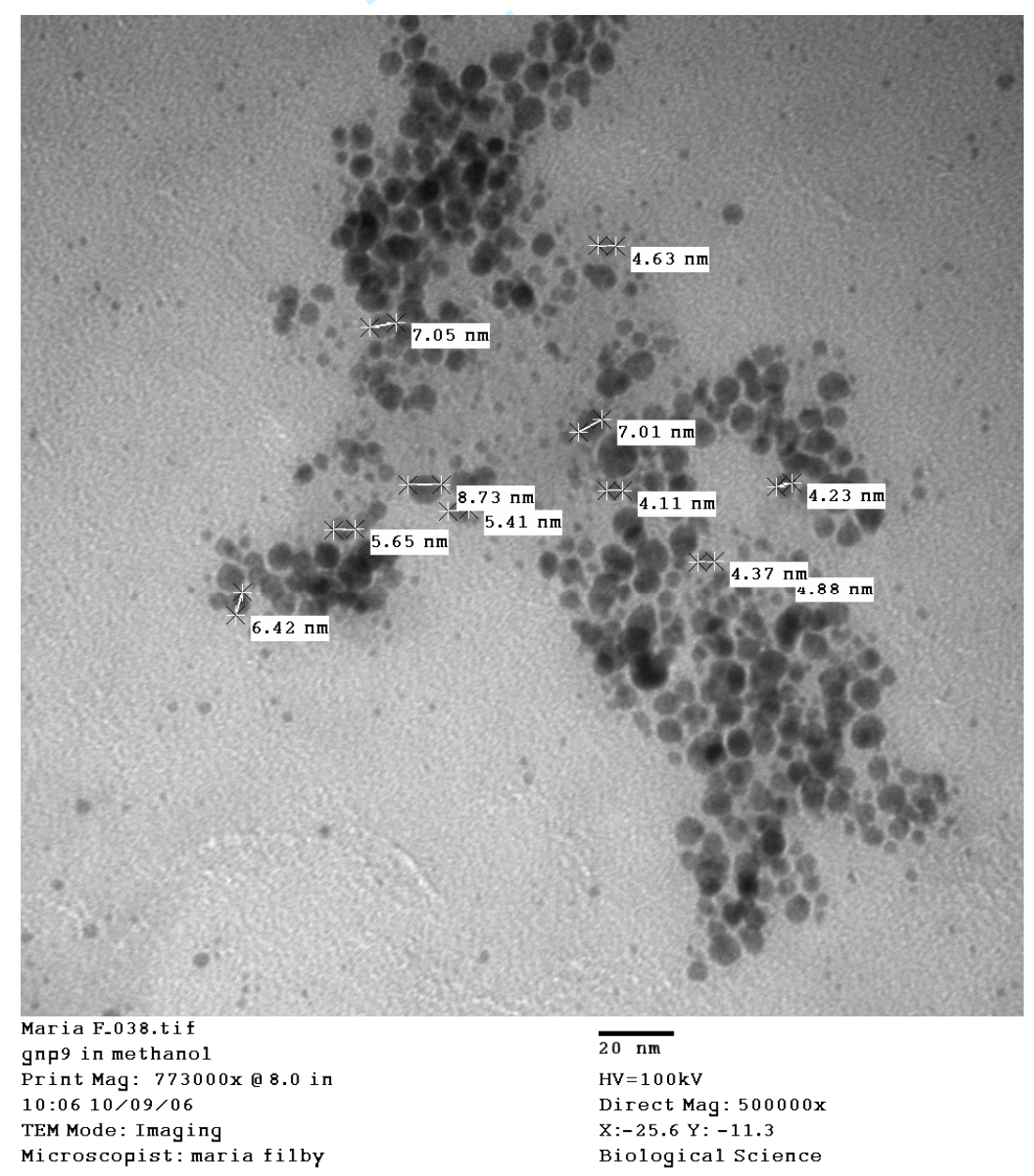

Figure S2 TEM image of functionalized gold nanoparticles $\mathbf{3}$ 
1

2

3

4

5

6

7

8

9

10

11

12

13

14

15

16

17

18

19

20

21

22

23

24

25

26

27

28

29

30

31

32

33

34

35

36

37

38

39

40

41

42

43

44

45

46

47

48

49

50

51

52

53

54

55

56

57

58

59

60

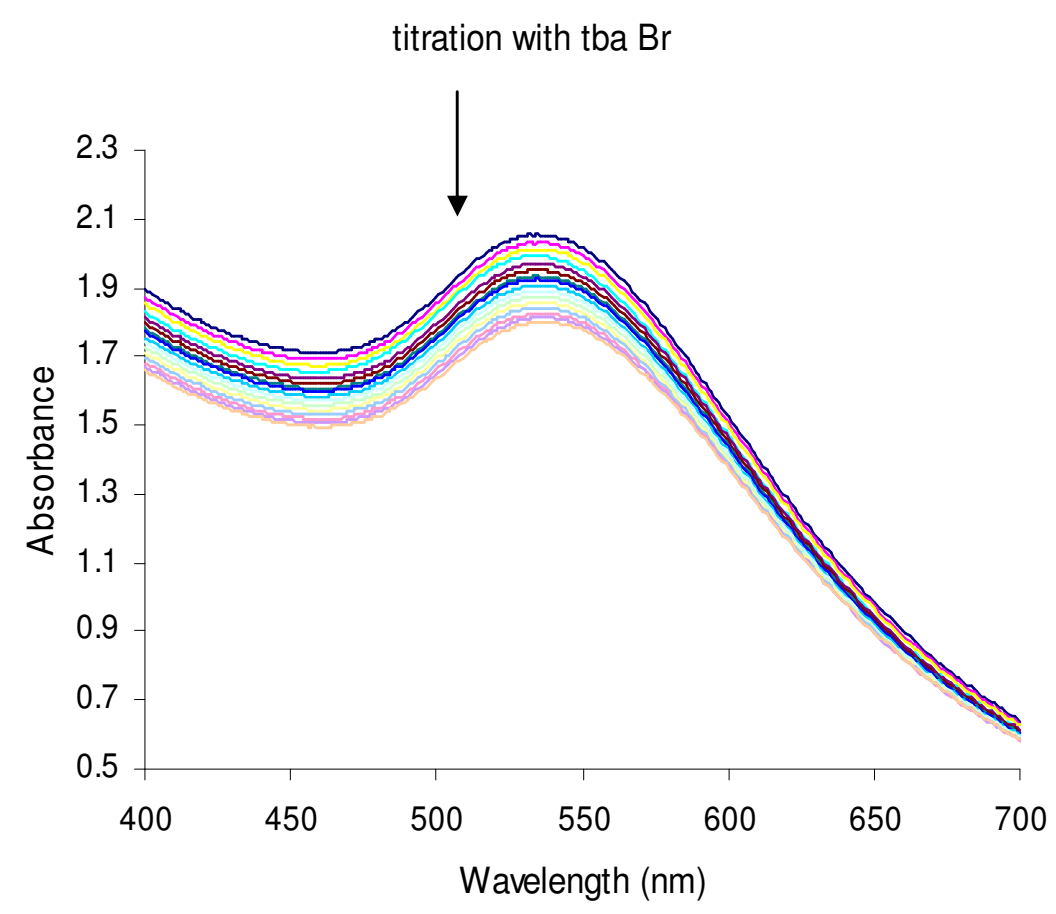

Figure S3 Titration of a gold nanoparticle 3 solution with $\mathrm{NBu}_{4} \mathrm{Br}$ in methanol.

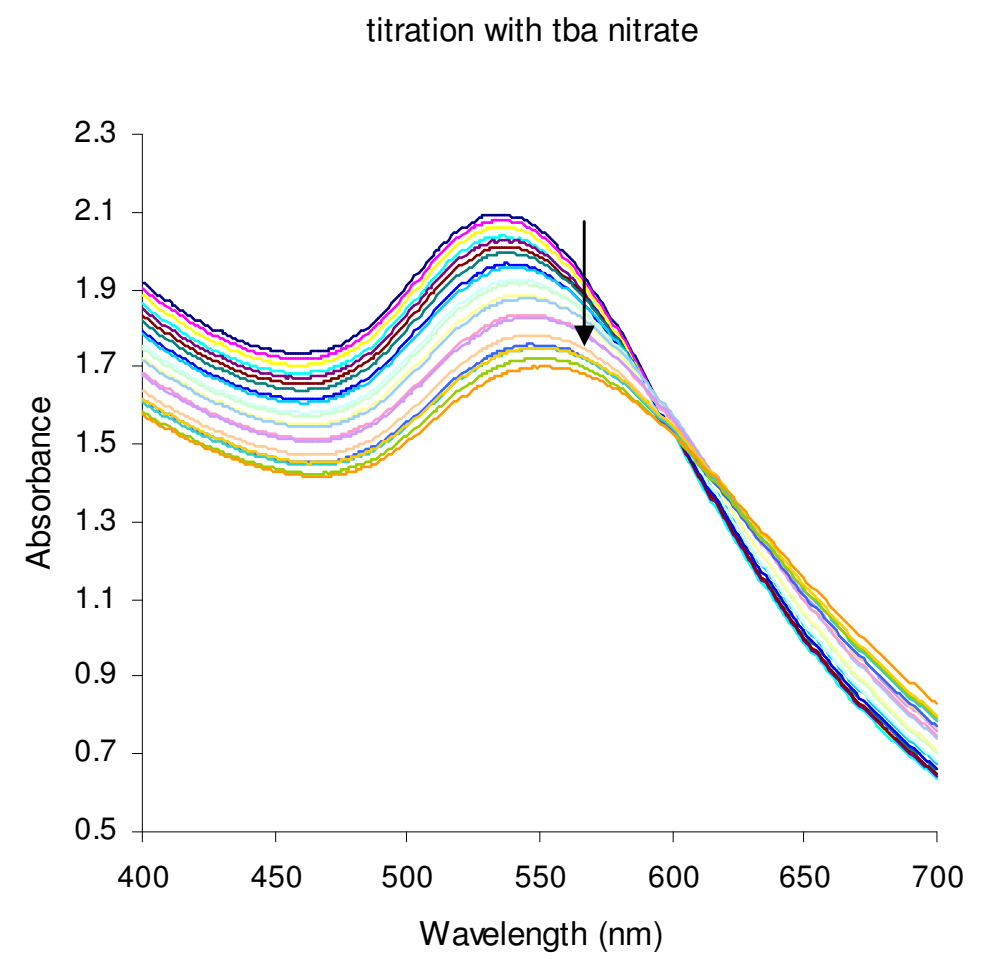

Figure S4 Titration of a gold nanoparticle 3 solution with $\mathrm{NBu}_{4} \mathrm{NO}_{3}$ in methanol. 
titration with silver tetrafluoroborate

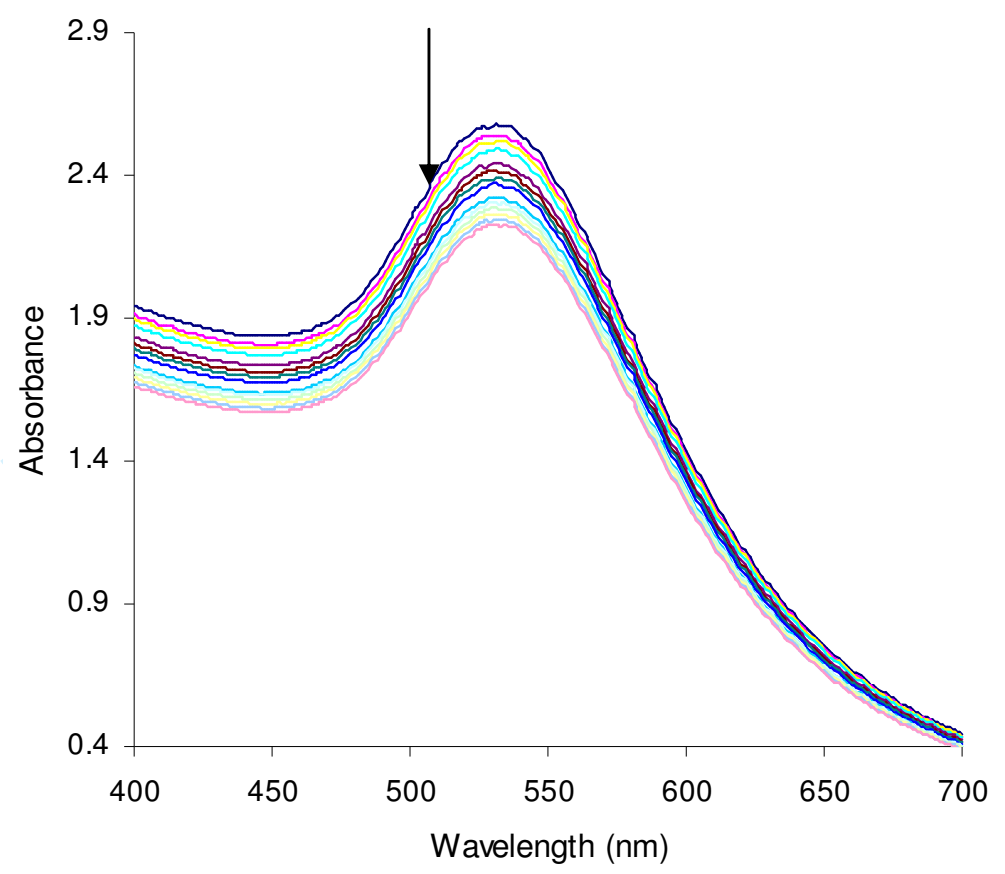

Figure S5 Titration of control dodecanethiol protected nanoparticles with $\mathrm{AgBF}_{4}$ in chloroform

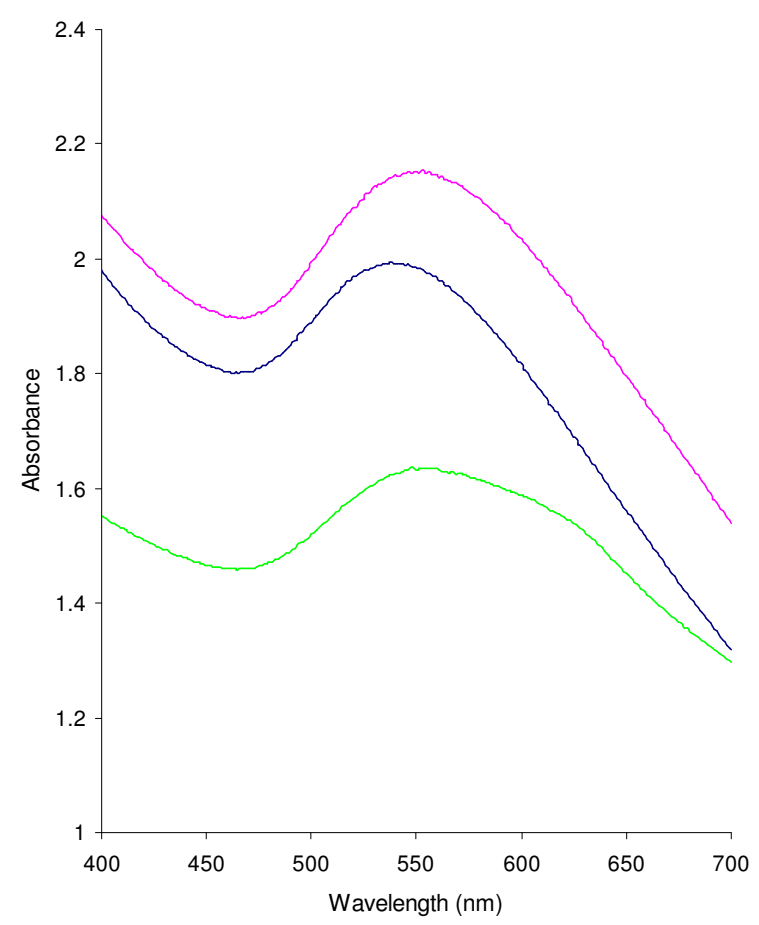

Figure S6 Titration of nanoparticles 3 with $\mathrm{AgNO}_{3}$ in $\mathrm{MeOH}$ (blue - before $\mathrm{AgNO}_{3}$ addition; magenta, after addition of one aliquot; green after addition of second aliquot). 


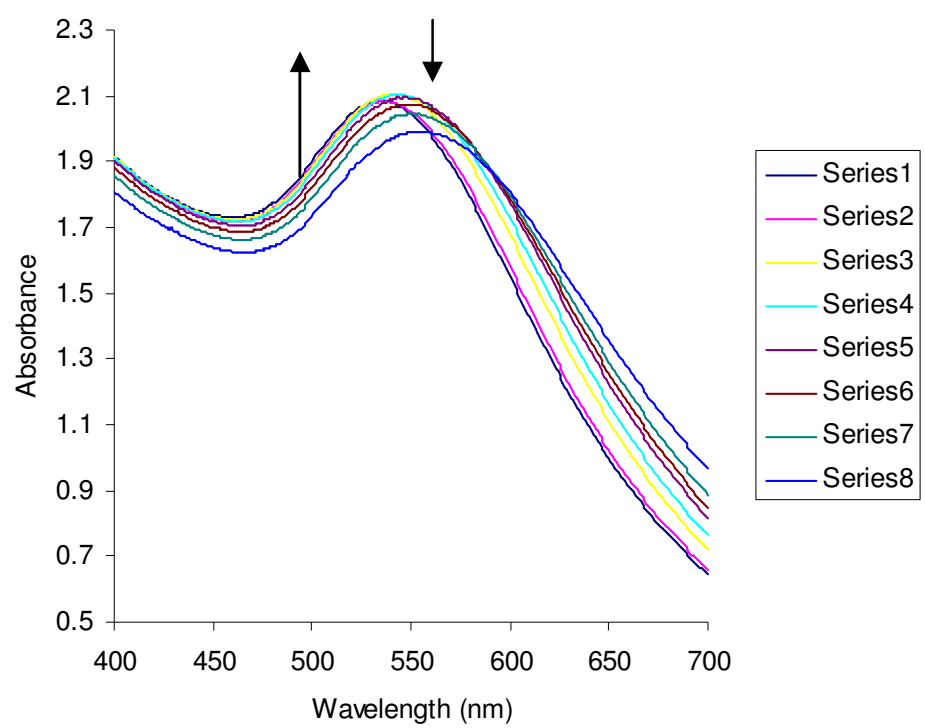

Figure S7 Titration of a gold nanoparticle solution 3 with $\mathrm{NBu}_{4} \mathrm{MeCO}_{2}^{-}$in methanol. Series 1 is the pure nanoparticle solution. 


\title{
Ion Pair Binding Functionalised Gold Nanoparticles
}

\author{
Maria H. Filby and Jonathan W. Steed \\ Department of Chemistry, Durham University, South Road, Durham, DH1 3LE, UK. \\ jon.steed@durham.ac.uk \\ RECEIVED DATE (to be automatically inserted after your manuscript is accepted if required \\ according to the journal that you are submitting your paper to) \\ Ion-Pair Binding Nanoparticles \\ Department of Chemistry, Durham University, South Road, Durham, DH1 3LE, UK. Tel: +44 \\ (0)191334 2085. Fax: +44 (0)191 384 4737. E-mail: jon.steed@durham.ac.uk
}

Pyridyl amide functionalise gold nanoparticles have been used to bind and sense simple anions and ion pairs by means of shifts in the intensity and wavelength of the nanoparticles' surface plasmon resonance absorption.

Keywords: gold nanoparticles, anion, ion pair, sensing, amide, supramolecular

In recent years there have been several studies aimed at attaching supramolecular anion recognition functionality to the surface of metallic nanoparticles, particularly gold. ${ }^{1-3}$ Nanoparticle attachment allows the coupling of selective binding functionality with the photophysical properties of the nanoparticle, namely the surface plasmon absorption band. ${ }^{4}$ Moreover binding to nanoparticles can serve to enhance the preorganisation of the receptor functionality by rigidifying and preorganising the binding 
pocket. ${ }^{1}$ This functionalisation of gold nanoparticles with ion recognition functionality provides an interesting potential ion sensing paradigm.

Recently we have shown that simple hydrogen bonding pyridyl ligands ${ }^{5-7}$ are capable of selfassembling with particular anion-metal combinations. This process results in discrete arrays held together by cooperative hydrogen bonding of anions such as $\mathrm{NO}_{3}^{-}$between pairs of ligands, coupled with simultaneous binding of the pyridyl functionality to the metal centre ${ }^{6,7}$ and this recognition motif can form the basis of a series of pyridinium anion-binding hosts ${ }^{8-13}$ and can be transferred to a polystyrene support. ${ }^{14}$ This work forms part of a growing body of interest in metal-based anion receptors. ${ }^{15-19}$ We now report the coupling of a self-assembled, labile ion-pair binding system to gold nanoparticles.
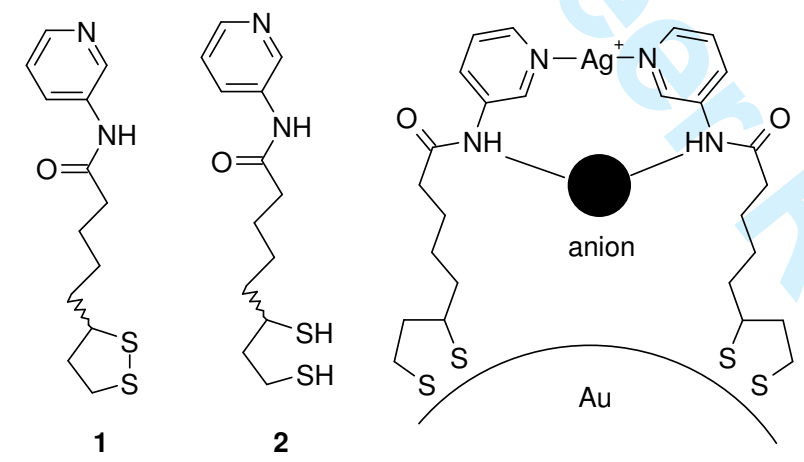

Figure 1: Structures of ligands 1 and 2 along with the proposed binding mode of the ligand-salt complex to the nanoparticle surface.

Ligands 1 and $\mathbf{2}$ were designed to incorporate a cation-ligating pyridyl group, an anion-binding amide and a disulfide or dithiol moiety capable of binding strongly to a gold nanoparticle surface. We anticipate a simultaneous anion and cation binding mode as shown in Figure 1. Beer et al. have reported $^{1}$ simple thioctic-acid aide derivatives capable of binding anions with association constants in the region of $10^{5} \mathrm{M}^{-1}$ and we anticipate an additional enhancement from the preorganisation imparted by attachment to the nanoparticle. Ligand $\mathbf{1}$ is readily synthesised by coupling of thioctic acid and 3aminopyridine with DCCI (3-dimethylamino-propyl)-ethyl-carbodiimide and HOBt (hydroxybenzatriazole hydrate) in dichloromethane. 

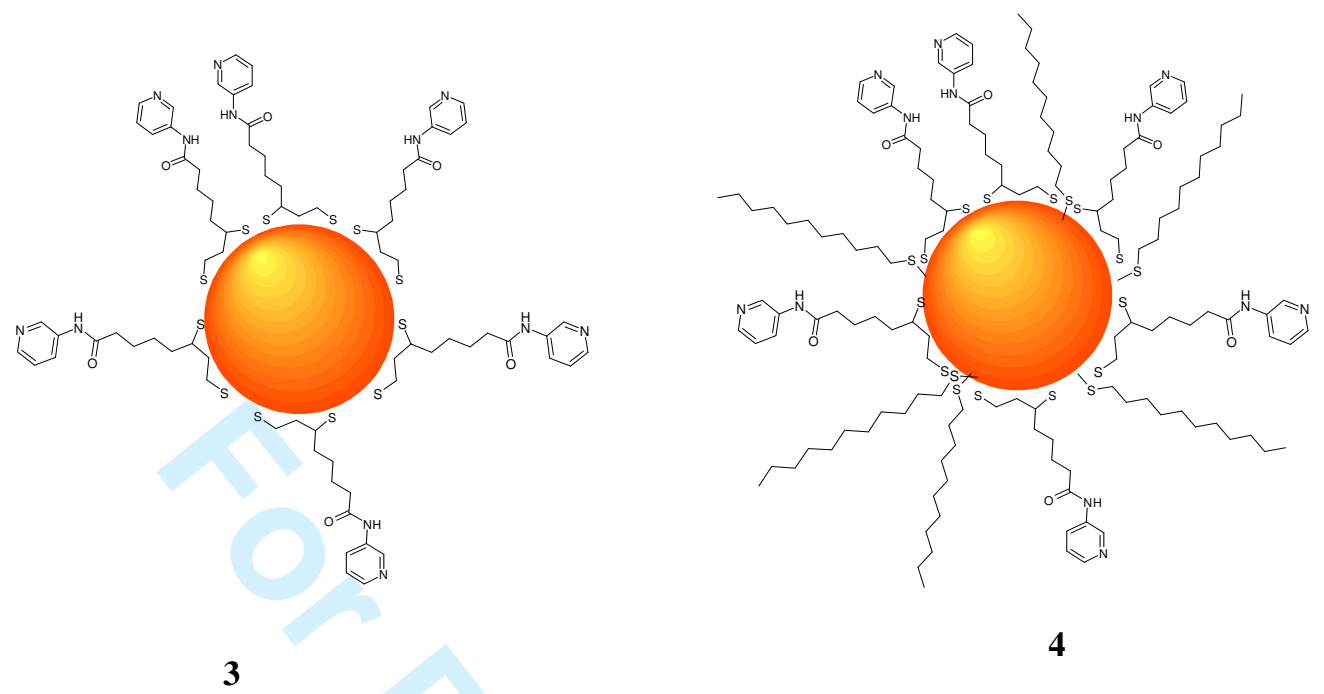

Figure 2: Schematıc representations of functionalised gold nanoparticles $\mathbf{3}$ and $\mathbf{4}$.

Gold nanoparticles were prepared by a literature method. ${ }^{20}$ The reduced gold was exposed to air after being stirred for ten minutes to quench any remaining reducing agent. Ligand $\mathbf{1}$ was then added (2 equivalents based on $\mathrm{HAuCl}_{4}$ ) and the mixture stirred for a further hour. The functionalised nanoparticles (3) precipitate readily from diglyme solution and were purified by ultracentrifugation and several washings with diethyl ether to remove any unreacted ligand, naphthalene and diglyme. The nanoparticles were then re-dissolved in methanol. TEM images confirm the presence of nanoparticles with sizes varying between ca. 4-9 $\mathrm{nm}$. The presence of the organic ligand was confirmed by TGA analysis which showed $c a .20 \%$ mass loss in the range $170-400{ }^{\circ} \mathrm{C}$. The nanoparticles remained stable and did not agglomerate in solution at room temperature over a period of 6 months. The solvent can be removed and the nanoparticles can be redispersed in a variety of solvents. Binding of the ligand to the nanoparticles was confirmed in this way by the observation of broadened ligand signals ${ }^{21}$ in the ${ }^{1} \mathrm{H}$ NMR spectrum of the functionalised nanoparticles methanol- $d_{4}$ (see SI). ${ }^{1} \mathrm{H}$ NMR spectroscopic resonances are characteristically broadened relative to those of free ligand because of spin-spin relaxational $\left(T_{2}\right)$ broadening, differences in Au-SR binding sites, and a gradient in monolayer packing density from near-core to ligand terminus with associated dipolar broadening. The IR spectra of ligands 
1 and 2 and of the functionalised nanoparticles (3) were recorded as KBr disks. Peaks observed at 634 $\mathrm{cm}^{-1}$ and $706 \mathrm{~cm}^{-1}$ were assigned to S-S and C-S stretching modes, respectively both of which disappear upon adsorption onto the gold surface. While nanoparticles derived from ligands $\mathbf{1}$ and $\mathbf{2}$ were broadly similar, those derived from the disulfide $\mathbf{1}$ proved to exhibit better long term stability and as a result we focused on this compound.

The UV-visible spectrum of the functionalised nanoparticles $\mathbf{3}$ in methanol solution showed a broad peak at $531 \mathrm{~nm}$ assigned to the nanoparticle surface plasmon resonance band. The measurement was repeated one week later without any sign of aggregation or ageing. ${ }^{22}$ The anion and cation binding ability of the functionalised nanoparticles was assessed by titration with potential guest species. In a typical experiment, $10 \mu \mathrm{L}$ aliquots of guest solution $\left(0.216 \mathrm{~mol} \mathrm{dm}^{-3}\right)$ were added to a $2 \mathrm{~mL}$ sample of the gold nanoparticle solution.

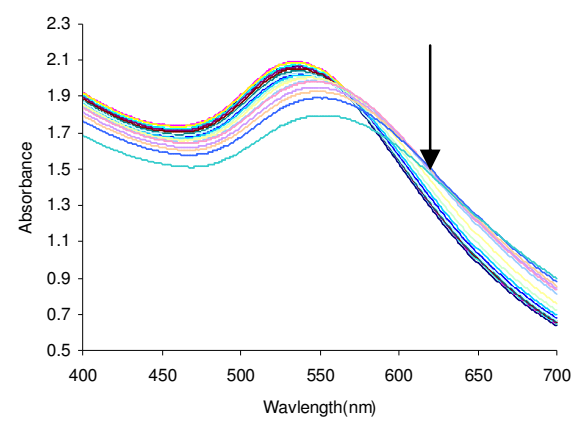

Figure 3 Titration of a gold nanoparticles 3 with $\mathrm{NBu}_{4} \mathrm{Cl}$ in methanol. The uppermost spectrum is the pure nanoparticle solution.

Figure 3 reveals a small red shift from 532 to $535 \mathrm{~nm}$ which occurs on addition of up to 6 aliquots of $\mathrm{Cl}^{-}$. Then on each further addition a much larger change is observable and the absorption maximum reaches $553 \mathrm{~nm}$ after an addition of a total of $0.1 \mathrm{~mL}$ of the anion solution. The change is ascribed to anion binding to the amide hydrogen bonding moiety of the ligand and consequent changes in the local index of refraction followed by nanoparticle cross-linking. Dyalysis of the solution to remove excess $\mathrm{NBu}_{4}{ }^{+} \mathrm{Cl}^{-}$did not result in any change in the absorption suggesting that binding is irreversible under the experimental conditions. In contrast, analogous titration with $\mathrm{Br}^{-}$resulted in no 
significant changes other than dilution effects (see supplementary data) indicating much weaker binding of the bromide anion. Titration with $\mathrm{NO}_{3}{ }^{-}$resulted in a similar change to that observed for chloride, however the binding appeared weaker as the shift had reached $550 \mathrm{~nm}$ only after an addition of $0.2 \mathrm{~mL}$ in total (see supplementary data). In the case of $\mathrm{Cl}^{-}, \mathrm{Br}^{-}$and $\mathrm{NO}_{3}{ }^{-}$there was a decrease in absorbance due to dilution effects. When the nanoparticle solution was titrated with $\mathrm{MeCO}_{2}^{-}$in the same way, however, an initial increase in absorbance and a red shift were observed after addition of up to 3 aliquots of anion solution followed by a decrease in absorbance and a further red shift, reaching $556 \mathrm{~nm}$ after an addition of only 8 aliquots (see SI). The reason for the increase in absorbance is unclear although it is possible that the subsequent decrease and red shift is due to excess acetate ions bridging between nanoparticles causing aggregation.

Since the functionalised nanoparticles appear to exhibit anion binding effects we turned our attention to cation binding, in particular using $\mathrm{Ag}(\mathrm{I})$ which is likely to interact strongly with the pyridyl groups as we have observed in related systems in solution. ${ }^{7}$ Titration of nanoparticles 3 with $\mathrm{AgBF}_{4}$ proved interesting, with a significant increase in the absorption in proportion with the amount of added $\mathrm{Ag}^{+}$ until a limiting spectrum was reached after addition of 4 aliquots, at which point further addition resulted in a decrease in absorption and a red shift, Figure 4 . It has been shown ${ }^{23}$ that nanoparticle surface plasmon absorption intensity increases with increasing thickness of a surrounding silica shell, although relatively thick $(10 \mathrm{~nm})$ shells are required. This observation is explained by an increase in significance of scattering. It is difficult to see how such a dielectric layer could form in this instance, however. An alternative explanation may be binding of $\operatorname{Ag}(\mathrm{I})$ to the surface of the nanoparticle itself resulting in a size increase and hence increase on absorption coefficient, although in this case a shift to longer wavelength would also be expected. When the layer deposition is saturated, the excess silver tetrafluoroborate may cause the gold nanoparticles to aggregate and eventually precipitate out of solution to give a final red shift and decrease in absorbance in the final spectrum. 


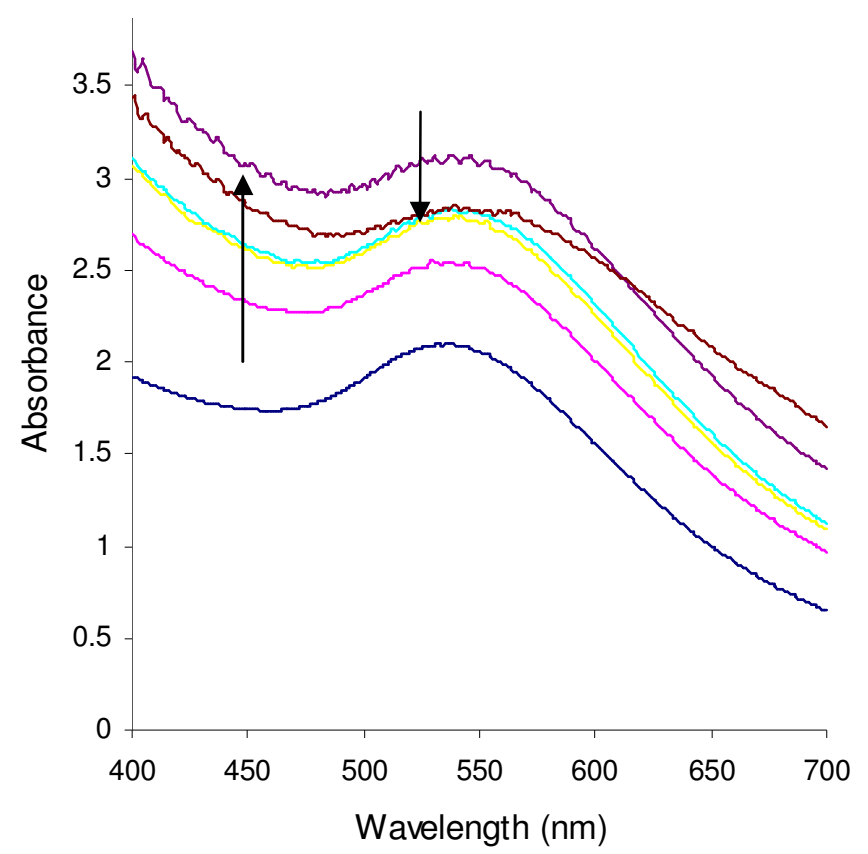

Figure 4 Titration of gold nanoparticles 3 solution with $\mathrm{AgBF}_{4}$ in methanol. The bottom spectrum is the pure nanoparticle solution.

Further interesting results were observed upon titration of functionalised nanoparticles 3 with $\mathrm{AgNO}_{3}$ solution. In related small molecule model systems we have shown a significant cooperativity between $\mathrm{Ag}^{+}$and $\mathrm{NO}_{3}{ }^{-}$binding. ${ }^{7}$ On addition of $\mathrm{AgNO}_{3}$ to a solution of $\mathbf{3}$ in methanol initially a significant increase in absorbance was observed, accompanied by a red shift from $535 \mathrm{~nm}$ to $550 \mathrm{~nm}$. On addition of a further aliquot of $\mathrm{AgNO}_{3}$, however, the absorbance rapidly decreased, accompanied by significant broadening, attributed to agglomeration and eventual precipitation of the nanoparticles. This behavior may be correlated to the initial formation of discrete assemblies followed by more open species on addition of excess nitrate in the small-molecule systems. Thus we speculate that the formation of a shell of bound ion pairs the type shown in Figure 1 might result in increased absorption, followed by agglomeration as $\mathrm{Ag}^{+}$and $\mathrm{NO}_{3}{ }^{-}$anions begin to cause cross-linking between nanoparticles. ${ }^{24,25}$

As a control we also examined dodecanethiol protected nanoparticles that lack ion-binding functionality. ${ }^{26}$ The nanoparticles were subjected to several UV-Vis titrations with anions in chloroform in the same way as $\mathbf{3}$ (the much more lipophilic dodecane thiolate protected nanoparticles are not soluble 
in methanol). There was no spectral change in any of the titrations with anions or $\mathrm{Ag}^{+}$other than a decrease in absorbance due to dilution effects. An attempt was also made at synthesizing ligand $\mathbf{1}$ protected nanoparticles using the Schiffrin method. ${ }^{27}$ However the nanoparticles precipitated within a course of several hours probably due to the formation of larger aggregates which hydrogen bond the ligand to an excess of bromide, an event which is more likely to occur in low polarity solvent such as chloroform.

We also examined a ligand exchange procedure to prepare mixed dodecanethiol / 1 protected nanoparticles. $^{1,2}$ One molar equivalent of ligand $\mathbf{1}$ to $\mathrm{HAuCl}_{4}$ was added to the dodecanethiol protected nanoparticles, followed by stirring for $24 \mathrm{~h}$. The nanoparticles were then precipitated with methanol, centrifuged and washed. The nanoparticles were redissoved in chloroform and the resulting mixed nanoparticles (4) were characterized by ${ }^{1} \mathrm{H}$ NMR spectroscopy, IR and TEM. The ${ }^{1} \mathrm{H}$ NMR spectrum reveals the ratio of dodecanethiol to ligand as $1.7: 1$ by integration. Broadening of the peaks is also noted, however not to such extent as it was seen in the pure ligand nanoparticles. This could be attributed to more regular size of the nanoparticles and slightly smaller diameter. ${ }^{28}$ The binding properties of the mixed monolayer protected nanoparticles 4 were also probed with UV-Vis titration in chloroform solution. There was only an observable change in SPR shift on addition of chloride anion. Interestingly the first addition produced larger red shift than in pure ligand nanoparticle solution, $\mathbf{3}$. This is most likely due to the solvent used of lower polarity promoting stronger hydrogen bonding. Subsequent additions produced further red shift until the SPR absorption reached $535 \mathrm{~nm}$ after which point the SPR band returned to almost its original position at $530 \mathrm{~nm}$. This behavior could be attributed to mobility of the ligands around on the surface of nanoparticle or insufficient density of ligand $\mathbf{1}$ on the nanoparticle surface to give cooperative binding.

The TEM images of nanoparticles 4 reveal much higher monodispersity than $\mathbf{3}$ with nanoparticles with and average diameters of around $5 \mathrm{~nm}$. The mixed nanoparticles (4) appear to be more agglomerated in comparison to pure dodecanethiol protected nanoparticles, Figure 5.

(a) 

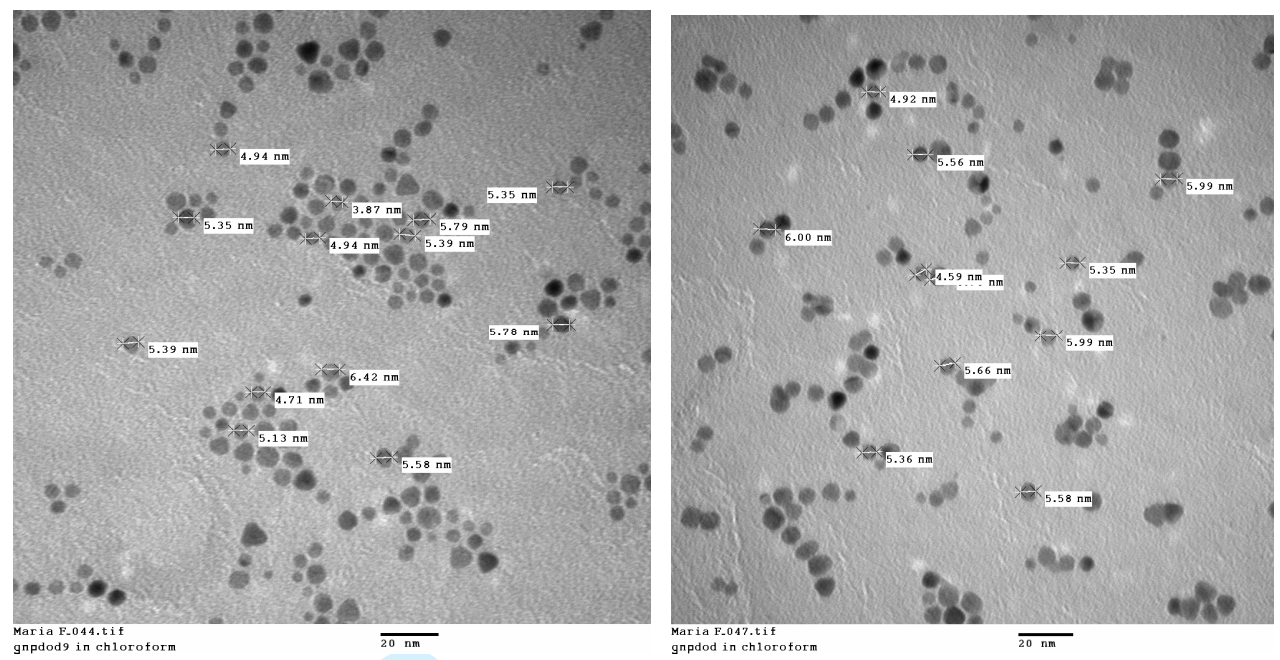

Figure 5 TEM images of mixed layer (dodecanethiol/ligand) functionalised nanoparticles 4 (a) and pure dodecanethiol protected nanoparticles (b).

Finally we also attempted to exchange citrate-stabilised commercial gold nanoparticles of an average diameter of 8-12 nm with ligand $\mathbf{1}$. The absorption wavelength of the citrate stabilized nanoparticles occurs at $524 \mathrm{~nm}$. Addition of small aliquots of methanolic solutions of various concentrations of 1 resulted in a profound red shift of the absorption wavelength (depending on concentration) and finally the nanoparticles precipitated out irreversibly. This behavior could be due to the ligand adsorbing onto the surface of gold and then binding the citrate anions still present in solution which could subsequently lead to formation of larger aggregates via hydrogen bonding interactions.

In conclusion we have shown that gold nanoparticles functionalised with simultaneous anion- and metal-binding ligands can exhibit mixed effects according to the ability of the anions to either bind to or cross-link nanoparticles. Silver(I) binding results in enhanced absorbance and simultaneous silver(I) and nitrate binding results in a cooperative effect in which enhanced absorption is observed in the presence of small amounts of $\mathrm{AgNO}_{3}$ but switching to agglomeration behavior on addition of excess metal salt.

\section{Experimental Section}


All purchased starting materials were of commercial quality and were used without further purification. Solvents were used as obtained unless mentioned otherwise. Dichloromethane was dried using a calcium hydride still. Diglyme (diethylene glycol dimethyl ether) was dried over sodium under vacuum. Reactions were carried out under air unless specifically mentioned. ${ }^{1} \mathrm{H}$ NMR spectra were run at room temperature using Bruker AV-400, Varian Inova-500, Varian Unity-300, Varian Mercury-200 NMR spectrometers at Durham University. Chemical shifts are reported in parts per million $(\delta)$ relative to tetramethylsilane as an internal reference. Mass spectra were run using a Micromass Autospec operating in EI or ES mode at Durham University. Micro-analysis for C, H, N were recorded at Durham University. IR spectra were collected using Perkin Elmer Spectrum 100 (spectral resolution $4 \mathrm{~cm}^{-1}$ ) as KBr discs. UV spectra were recorded on Perkin Elmer Lambda 900 UV/VIS/NIR spectrometer.

\section{5-[1,2]Dithiolan-3yl-pentanoic acid pyridin3-ylamide (1).}

Thioctic acid (0.825g $4.0 \mathrm{mmol})$ and (3-dimethylamino-propyl)-ethyl-carbodiimide (EDC) (0.621g 4.0 mmol) were dissolved in dichloromethane $(70 \mathrm{~mL})$ and stirred for $2 \mathrm{~h}$. Hydroxybenzatriazole hydrate (HoBt) $(0.540 \mathrm{~g} 4 \mathrm{mmol})$ was added followed by 3 -aminopyridine $(0.37 \mathrm{~g} 4 \mathrm{mmol})$. The reaction mixture was stirred at room temperature for 24 hours. The solvent was then removed under vacuum and the resultant oil was washed several times with water until pure. ${ }^{\mathbf{1}} \mathbf{H} \mathbf{N M R}\left(\mathbf{C D C l}_{\mathbf{3}}, \mathbf{J} / \mathbf{H z}, \boldsymbol{\delta} / \mathbf{p p m}\right): 1.38$ 1.44 (m, 2H, CH2), 1.48-1.68 (m, 4H, CH$), 1.81-1.83$ (q, J=6.8, 1H, He), 2.34 (t, J=6.8, 1H, Hd), 2.362.41 (m, 2H, Hb), 3.00-3.12 (m, 2H, Ha), 3.47-3.51 (m, 1H, Hc), 7.21 (dd, J=4.8, 8.4, 1H, PyH), 8.13 (ddd, $J=1.6,2,8.4,1 \mathrm{H}$, PyH), 8.25 (dd, $J=1.6,4.8,1 \mathrm{H}$, PyH), 8.33 ( br, s, 1H, NH), 8.51 (d, $J=2,1 \mathrm{H}$, PyH). ES ${ }^{+}$-MS: $\mathrm{m} / \mathrm{z}=281[\mathrm{M}+\mathrm{H}]^{+}$. Anal: Calc. for $\mathrm{C}_{13} \mathrm{H}_{18} \mathrm{~N}_{2} \mathrm{OS}_{2}: \mathrm{C}, 55.28, \mathrm{H}, 6.42, \mathrm{~N}, 9.91$. Calc. for $\mathrm{C}_{13} \mathrm{H}_{18} \mathrm{~N}_{2} \mathrm{OS}_{2}+0.25 \mathrm{H}_{2} \mathrm{O}: \mathrm{C}, 53.57, \mathrm{H}, 6.57, \mathrm{~N}, 9.61$. Found: C, 53.24, H, 6.30, N, 8.96. IR (v/cm $\left.{ }^{-1}\right)$ : 3420w (NH); 558w (S-S).

6,8-Dimercapto-octanoic acid pyridin-3-ylamide (2). 
Compound 1 (3.83 g, $10 \mathrm{mmol})$ was dissolved in $50 \mathrm{~mL}$ of 1:1 EtOH/water with stirring. $\mathrm{NaBH}_{4}(416$ $\mathrm{mg}, 11 \mathrm{mmol}$ ) was added and stirred for $60 \mathrm{~min}$ or until the solution became colorless. The reaction mixture was diluted with water $(100 \mathrm{~mL})$ and extracted with $\mathrm{CHCl}_{3}(3 \times 75 \mathrm{~mL})$. The combined organic phases were dried over magnesium sulfate $\left(\mathrm{MgSO}_{4}\right)$, filtered, and evaporated to result in colourless oil. ${ }^{1} \mathbf{H} \mathbf{N M R}\left(\mathbf{C D C l}_{\mathbf{3}}, \mathbf{J} / \mathbf{H z}, \boldsymbol{\delta} / \mathbf{p p m}\right): 1.23(\mathrm{~d}, J=8,1 \mathrm{H}, \mathrm{SH}), 1.29(\mathrm{t}, J=8,1 \mathrm{H}, \mathrm{SH}), 1.40-1.43(\mathrm{~m}, 2 \mathrm{H}$, $\left.\mathrm{CH}_{2}\right), 1.44-1.58\left(\mathrm{~m}, 2 \mathrm{H}, \mathrm{CH}_{2}\right), 1.58-1.68\left(\mathrm{~m}, 2 \mathrm{H}, \mathrm{CH}_{2}\right), 1.81-1.83$ (q, J=7.6, 2H), 2.35 (t, J=7.6, 1H), 2.58-2.68 (m, 2H), 2.84 (b,m, 1H), 7.21 (dd, J=4.8, 8.4, 1H, PyH), 8.13 (ddd, J=1.6, 2, 8.4, 1H, PyH), $8.25\left(\mathrm{dd}, J=1.6,4.8,1 \mathrm{H}\right.$, PyH), 8.33 (br, s, 1H, NH), 8.51 (d, J=2, 1H, PyH). ES ${ }^{+}-\mathbf{M S}: \mathrm{m} / \mathrm{z}=$ $283[\mathrm{M}+\mathrm{H}]^{+}$. IR $\left(\mathbf{v} / \mathbf{c m}^{-1}\right)$ : 3420w (NH); $2536 \mathrm{w}(\mathrm{S}-\mathrm{H})$. Anal: Calcd. for $\mathrm{C}_{13} \mathrm{H}_{20} \mathrm{~N}_{2} \mathrm{OS}{ }_{2}: \mathrm{C}, 55.28, \mathrm{H}, 6.42$, N, 9.91. Calcd. for $\mathrm{C}_{13} \mathrm{H}_{18} \mathrm{~N}_{2} \mathrm{OS}_{2}+0.5 \mathrm{H}_{2} \mathrm{O}$ : C, 53.20, H, 7.21, N, 9.54. Found: C, 53.62, H, 6.73, N, 9.37.

\section{Synthesis of gold nanoparticles 3.}

Sodium naphthalenide was prepared by adding sodium $(100 \mathrm{mg})$ to a dry solution of naphthalene (410 $\mathrm{mg}$ ) in $35 \mathrm{~mL}$ of diglyme. The mixture was degassed and filled with $\mathrm{N}_{2}$ three times in a Schlenk and then sonicated whilst under vacuum until dark green solution appeared. $\mathrm{HAuCl}_{4}\left(30 \mathrm{mg}, 8.83 \times 10^{-5}\right.$ moles) was dissolved in $20 \mathrm{~mL}$ of dry diglyme in a Schlenk to which the sodium napthalenide reducing solution was added dropwise until the orange gold solution has turned purple. The colloidal suspension was then exposed to air atmosphere to ensure all the reducing agent is quenched and stirred for 3-4 min. Ligand 1 (0.068 g, $0.17 \mathrm{mmol})$ was dissolved in $10 \mathrm{~mL}$ of diglyme and the resulting solution was added slowly to the reduced gold nanoparticle colloid and stirred for $1 \mathrm{~h}$. The precipitated nanoparticles were then centrifuged and the supernatant decanted. The nanoparticles pellet was washed aided with sonication in ethanol three times to remove any remaining diglyme and $\mathbf{1}$. The final pellet was resuspended in $40 \mathrm{~mL}$ of methanol aided by gentle sonication for 2-3 min.

The nanoparticles were characterised by TGA which showed a $c a .20 \%$ mass loss with onset temperature $170{ }^{\circ} \mathrm{C}$, occurring gradually over the temperature range $170-400{ }^{\circ} \mathrm{C}$ indicative of loss of the organic ligand. 


\section{Synthesis of mixed-ligand gold nanoparticles 4.}

The method of Brust et $a .^{26}$ was used to prepare tetraalkyl ammonium bromide protected nanoparticles. $\mathrm{HAuCl}_{4}(0.3537 \mathrm{~g}, 0.95 \mathrm{mmol})$ was dissolved in $30 \mathrm{~mL}$ of $\mathrm{H}_{2} \mathrm{O}$. Trioctyl propyl ammonium bromide (1.9 g, $4.0 \mathrm{mmol})$ was dissolved in $80 \mathrm{~mL}$ of toluene. Both solutions were combined and stirred vigorously for 10 min. A solution of $\mathrm{NaBH}_{4}\left(0.38 \mathrm{~g}\right.$ in $25 \mathrm{~mL}$ of $\left.\mathrm{H}_{2} \mathrm{O}\right)$ was then added dropwise to the stirred reaction over a period of 30 min ensuring that organic and aqueous phases were mixed together. The resulting deep red colloidal solution was stirred for further $20 \mathrm{~min}$. The organic phase was extracted and washed once with diluted $\mathrm{H}_{2} \mathrm{SO}_{4}$ (for neutralization) and five times with distilled water. The organic layer was then dried with $\mathrm{Na}_{2} \mathrm{SO}_{4}$.

To $20 \mathrm{~mL}$ of this tetraalkyl ammonium bromide protected nanoparticles stock solution was added dodecanethiol solution in acetone $\left(4.62 \times 10^{-3} \mathrm{M}\right)(93.6 \mathrm{mg}$ in $100 \mathrm{~mL})$. The reaction mixture was stirred for $2 \mathrm{~h}$. It was then precipitated with methanol, centrifuged and washed several times with methanol and then ether to give dodecanethiol-protected nanoparticles which were then redissolved in chloroform.

Compound 1 (66 mg, $0.24 \mathrm{mmol}$ ) was dissolved in $10 \mathrm{~mL}$ of chloroform and added to the chloroform solution of the dodecane-thiol protected nanoparticles $(20 \mathrm{~mL})$ which contained $20 \mathrm{~mL}$ of the original stock solution of the tetraalkyl ammonium bromide protected nanoparticles (approx. 0.24 mmol of Au). The reaction mixture was stirred for $24 \mathrm{~h}$. The nanoparticles were then precipitated with methanol, centrifuged and washed several times with methanol and then ether. The nanoparticles were then redissolved in chloroform for further study.

\section{Centrifugation experiment}

Gold nanoparticles 3 were centrifuged at 11,000 xg for $2 \mathrm{~h}$ and re-dissolved in absolute ethanol. The concentration was adjusted to identical one of the methanol colloid by observing the absorption curve. 2 $\mathrm{mL}$ of the stock solution was then titrated with $0.216 \mathrm{M}$ solution of tba- $\mathrm{Cl}$ in ethanol. After an addition of $0.1 \mathrm{~mL}$ of the anion solution, the surface Plasmon resonance peak shifted from $532 \mathrm{~nm}$ to 553 as it 
was observed in the methanol colloid of gold. The solution was then placed in a dialysis tubing cellulose membrane (Aldrich) of M.W.12,400 cut off. The tubing was left in a 250mL beaker of ethanol to dialyse any free tba- $\mathrm{Cl}$ out overnight. The absorption spectrum was taken the following day and has shown no change in the resonance peak. To confirm the permeability of the cellulose tubing to tba- $\mathrm{Cl}$ in ethanol a reverse experiment was undertaken in which gold nanoparticles $\mathbf{3}$ in ethanol were placed in a dialysis tube inside a beaker containing $250 \mathrm{~mL}$ of tba-Cl solution $(0.216 \mathrm{M})$. The tube was left overnight and the electronic absorption was recorded the following day. The spectrum exhibited the characteristic drop in absorbance and red shift characteristic of chloride binding by 3 .

We thank the EPSRC for a studentship (M. H. F.).

\section{References}

(1) Beer, P. D.; Cormode, D. P.; Davis, J. J., Chem. Commun. 2004, 414-415.

(2) Watanabe, S.; Sonobe, M.; Arai, M.; Tazume, Y.; Matsuo, T.; Nakamura, T.; Yoshida, K., Chem. Commun. 2002, 2866-2867.

(3) Astruc, D.; Daniel, M. C.; Ruiz, J., Chem. Commun. 2004, 2637-2649.

(4) Moores, A.; Goettmann, F., New J. Chem. 2006, 30, 1121-1132.

(5) Turner, D. R.; Smith, B.; Goeta, A. E.; Evans, I. R.; Tocher, D. A.; Howard, J. A. K.; Steed, J. W., CrystEngComm 2004, 6, 633-641.

(6) Turner, D. R.; Spencer, E. C.; Howard, J. A. K.; Tocher, D. A.; Steed, J. W., Chem. Commun. 2004, 1352-1353.

(7) Turner, D. R.; Smith, B.; Spencer, E. C.; Goeta, A. E.; Evans, I. R.; Tocher, D. A.; Howard, J. A. K.; Steed, J. W., New J. Chem. 2005, 29, 90-98.

(8) Filby, M. H.; Humphries, T. D.; Turner, D. R.; Kataky, R.; Kruusma, J.; Steed, J. W., Chem. Commun. 2006, 156-158.

(9) Filby, M. H.; Steed, J. W., Coord. Chem. Rev. 2006, 250, 3200-3218.

(10) Zhang, J.; Bond, A. M.; Belcher, J.; Wallace, K. J.; Steed, J. W., J. Phys. Chem. B 2003, 107, 5777-5786.

(11) Wallace, K. J.; Belcher, W. J.; Turner, D. R.; Syed, K. F.; Steed, J. W., J. Am. Chem. Soc. 2003, 125, 9699-9715.

(12) Turner, D. R.; Paterson, M. J.; Steed, J. W., J. Org. Chem. 2006, 71, 1598-1608.

(13) Belcher, W. J.; Fabre, M.; Farhan, T.; Steed, J. W., Org. Biomol. Chem. 2006, 4, 781-786.

(14) Russell, J. M.; Parker, A. D. M.; Radosavljevic-Evans, I.; Howard, J. A. K.; Steed, J. W., Chem. Commun. 2006, 269-271.

(15) Steed, J. W., Chem. Commun. 2006, 2637-2649.

(16) Nieto, S.; Pérez, J.; Riera, L.; Riera, V.; Miguel, D., New J. Chem. 2006, 30, 838-841.

(17) Wallace, K. J.; Daari, R.; Belcher, W. J.; Abouderbala, L. O.; Boutelle, M. G.; Steed, J. W., J. Organomet. Chem. 2003, 666, 63-74.

(18) Bondy, C. R.; Gale, P. A.; Loeb, S. J., Chem. Commun. 2001, 729-730.

(19) Bondy, C. R.; Gale, P. A.; Loeb, S. J., J. Am. Chem. Soc. 2004, 126, 5030-5031. 
(20) Schulz-Dobrick, M.; Sarathy, K. V.; Jansen, M., J. Am. Chem. Soc. 2005, 127, 12816-12817.

(21) Batten, S. R.; Hoskins, B. F.; Moubaraki, B.; Murray, K. S.; Robson, R., Chem. Commun. 2000, 1095-1096.

(22) Chechik, V., J. Am. Chem. Soc. 2004, 126, 7780-7781.

(23) LizMarzan, L. M.; Giersig, M.; Mulvaney, P., Langmuir 1996, 12, 4329-4335.

(24) Kim, T.; Lee, K.; Gong, M. S.; Joo, S. W., Langmuir 2005, 21, 9524-9528.

(25) Tilaki, R. M.; Zad, A. I.; Mahdavi, S. M., J. Nanoparticle Res. 2007, 9, 853-860.

(26) Brust, M.; Walker, M.; Bethell, D.; Schiffrin, D. J.; Whyman, R., J. Chem. Soc.-Chem. Commun. 1994, 801-802.

(27) Fink, J.; Kiely, C. J.; Bethell, D.; Schiffrin, D. J., Chem. Mat. 1998, 10, 922-926.

(28) Hostetler, M. J.; Wingate, J. E.; Zhong, C. J.; Harris, J. E.; Vachet, R. W.; Clark, M. R.; Londono, J. D.; Green, S. J.; Stokes, J. J.; Wignall, G. D.; Glish, G. L.; Porter, M. D.; Evans, N. D.; Murray, R. W., Langmuir 1998, 14, 17-30.

Supporting Information Available: ${ }^{1} \mathrm{H}$ NMR spectra of functionalised gold nanoparticles 3 and free ligand 1, TEM image of functionalized gold nanoparticles 3, UV-Vis spectra for titration of gold nanoparticles 3 with $\mathrm{Br}^{-}, \mathrm{NO}_{3}^{-}$and $\mathrm{MeCO}_{2}^{-}$in methanol. UV-Vis spectra for titration of control dodecanethiol protected nanoparticles with $\mathrm{AgBF}_{4}$ in chloroform and for titration of nanoparticles $\mathbf{3}$ with $\mathrm{AgNO}_{3}$ in $\mathrm{MeOH}$.

Synopsis for TOC

Gold nanoparticles functionalised with amidopyridine units bind and sense anions and cations simultaneously. 


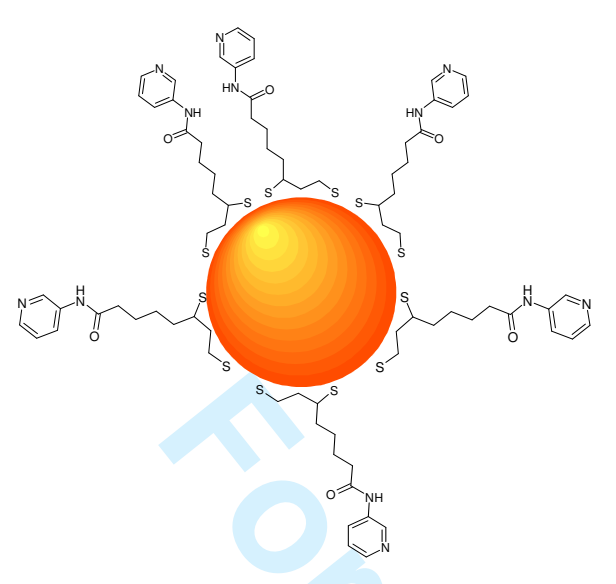

3

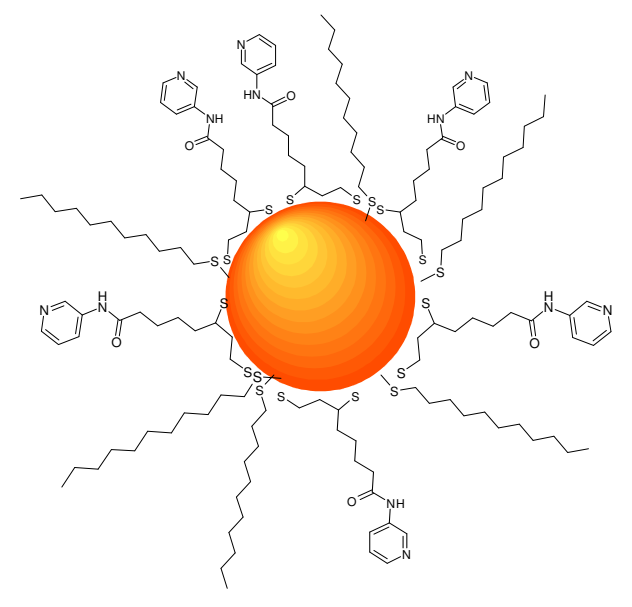

4 


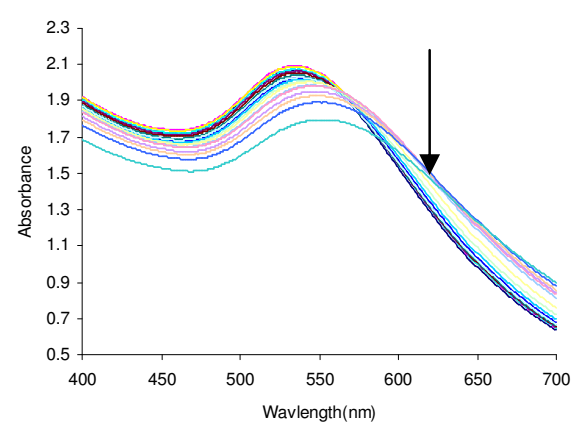


1

2

3

4

5

6

7

8

9

10

11

12

13

14

15

16

17

18

19

20

21

22

23

24

25

26

27

28

29

30

31

32

33

34

35

36

37

38

39

40

41

42

43

44

45

46

47

48

49

50

51

52

53

54

55

56

57

58

59

60 54 (5)

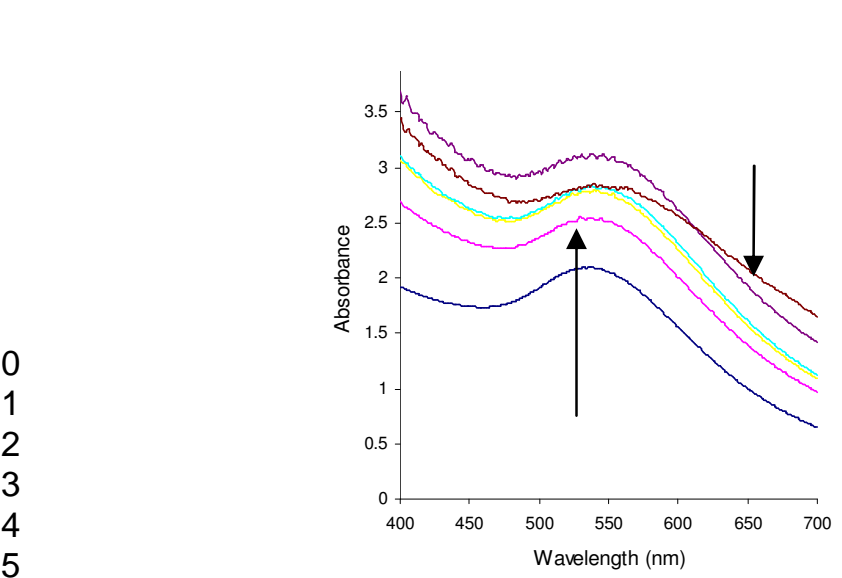 \\ Page 21 of $23 \quad$ Supramolecular Chemistry}

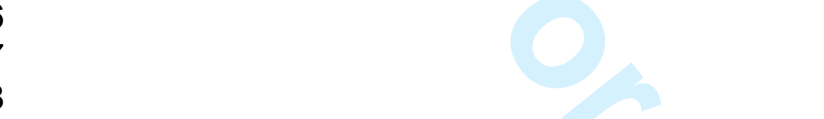

(1)

.

4

.

(1)

.

.

57 


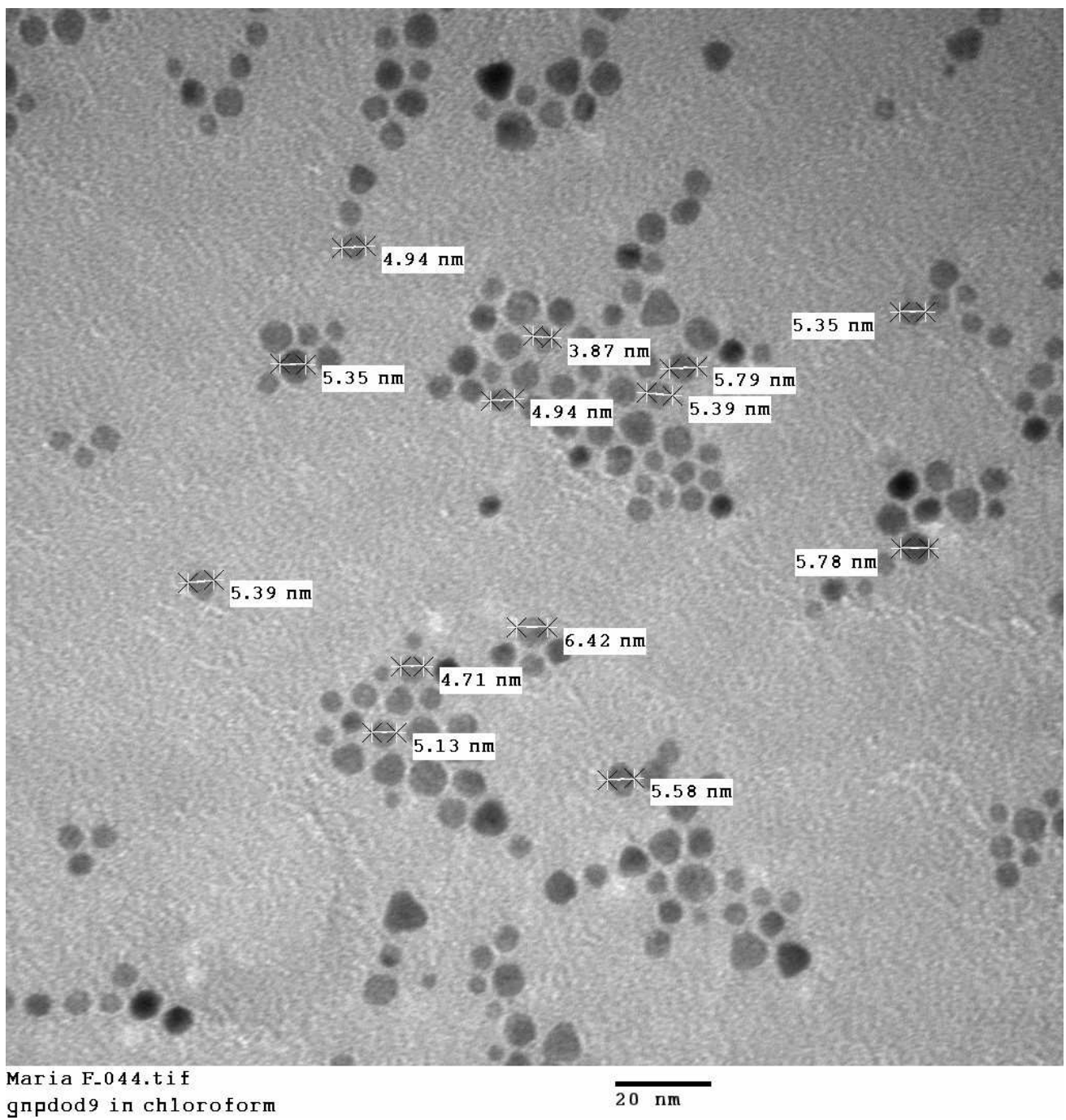

Fig $5 a$

$270 \times 284 \mathrm{~mm}(96 \times 96 \mathrm{DPI})$ 


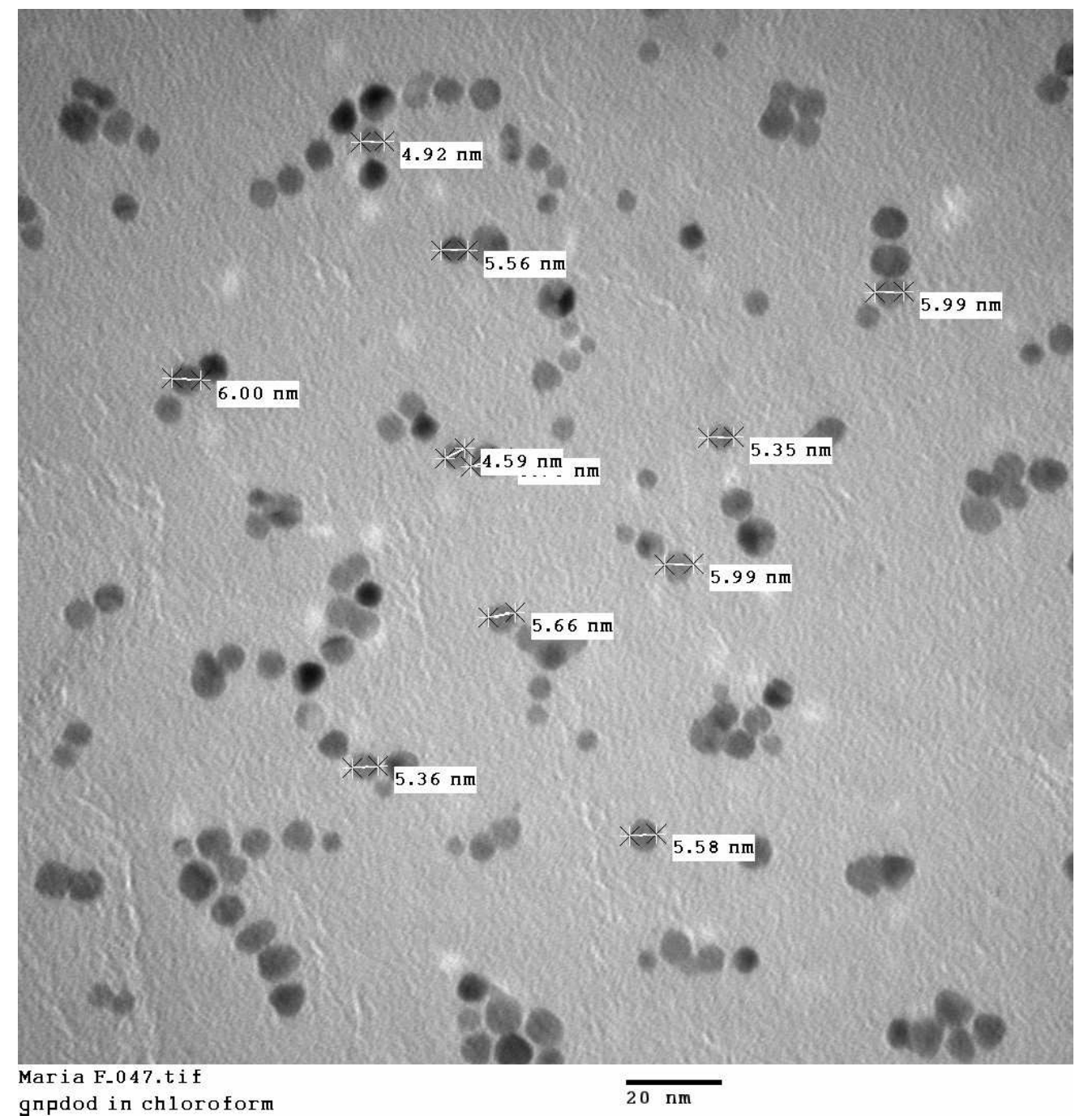

Fig. 5b

$270 \times 284 \mathrm{~mm}(96 \times 96$ DPI) 